carbon caused a fivefold to sixfold decrease in production of toxins, although removing phosphorus had no effect. ${ }^{13}$

After the Rutland incident the Department of Health warned recreational users to avoid contact with algal scum and water close to it, and this message has been incorporated into a leaflet issued by the National Rivers Authority. The authority regularly monitors the quality of inland waters and now screens for the presence of blooms of potentially toxic bluegreen algae.

Toxic algae have already killed many animals, and humans are also at risk of illness and death. Better understanding of the biochemistry, physiology, and toxicology of cyanobacteria is needed to keep these risks to a minimum.

Director of Public Health,

JAMES M DUNLOP

Hull Health Authority, Hull HU2 8TD
1 Francis G. Poisonous Australian lake. Nature 1878;18:11-2

Collins M. Algal toxins. Microbiol Rev 1978;42:725-46.

Beasley VR, Cook WO, Dahlem AM, Hooser SB, Lovell RA, Valentine WM. Algae intoxication in livestock and waterfowl. Vet Clin North Am Food Anim Pract 1989;5:345-61.

4 Corkill N, Smith R, Seckington M, Pontefract R. Poisoning at Rutland Water. Vet Re 1989;125:356.

5 Lindholm T, Eriksson JE, Meriluoto JAO. Toxic cyanobacteria and water quality problemsexamples from a eutrophic lake on Aland, south west Finland. Water Research 1989;23:481-6.

6 Codd GA. Cyanobacterial poisoning in British freshwaters. Vet Rec 1983;34:223-4.

Repavich WM, Sonzogni WC, Standridge JH, Wedepohl RE, Meisner LF. Cyanobacteria (Blue green algae) in Wisconsin waters: acute and chronic toxicity. Water Research 1990;24:225-31.

8 Turner PC, Gammie AJ, Hollinrake K, Codd GA. Pneumonia associated with contact with cyanobacteria. $B M F$ 1990;300:1440-1.

9 Long EG, Ebrahimzadeh A, White EH, Swisher B, Callaway CS. Alga associated with diarrhoea in patients with acquired immunodeficiency syndrome and in travellers. $f$ Clin Microbiol 1990;28:1101-4.

10 Falconer IR, Buckley TH. Tumour promotion by Microcystis sp, a blue-green alga occurring in water supplies. Med f Aust 1989;150:351.

11 Beasley VR, Coppock RW, Simon J, et al. Apparent blue-green algae poisoning in swine subsequent to ingestion of a bloom dominated by Anabaena spiroides. 7 Am Vet Med Assoc $1983 ; 182: 413-4$.

12 Smith VH, Willin E, Karlsson B. Predicting the summer peak biomass of four species of blue-green algae (Cyanophyta/Cyanobacteria) in Swedish lakes. Water Research Bulletin 1987;23:397-402.

13 Codd GA, Bell SG, Brooks WP. Cyanobacterial toxins in water. Water Science Technolog 1989;21:1-13.
Exposure to ionising radiations either in utero or when young increases the risk of childhood leukaemia, but such exposures are estimated to account for only a small proportion of all cases. The causes of most cases are unknown. Recent work on the aetiology of childhood leukaemia has been stimulated by finding geographical clusters of the disease associated with nuclear plants. The most notable cluster was in the village of Seascale, adjacent to the Sellafield nuclear reprocessing plant in Cumbria. ${ }^{1}$ Conventional radiobiological explanations are inadequate to explain this and other clusters around Dounreay $^{2}$ and Aldermaston and Burghfield, ${ }^{3}$ because of the very low doses of radiation to which the populations are estimated to have been exposed. There has been a search for other explanations using case-control studies which compare possible aetiological factors for cases and matched control children in areas where an apparent excess of cases has occurred.

Case-control studies of this kind are difficult both to conduct and to interpret. Some of the cases may have been diagnosed years before a study is done, and parents have to be located and asked to recall events in the distant past. Parents of a child who has been seriously ill and may have died may respond to questions differently from the parents of a healthy child-potentially a serious source of bias, especially when the case is one of a cluster that has attracted media interest and public speculation about possible causes.

The first of these studies, based on cases of childhood leukaemia and lymphoma in West Cumbria, produced unexpected findings. ${ }^{+}$Comparison of the questionnaire responses from parents of cases and controls did not provide evidence of appreciable differences between the two groups with respect to the exposures examined. But even if differences had been shown the findings may have been difficult to evaluate because responses had been obtained from only about $74 \%$ of the parents of cases and $55 \%$ of the parents of controls. ${ }^{5}$ Perhaps the most reliable information in the study, for which bias was unlikely, was on parental occupational exposure to radiation. This was obtained by linking case and control records to employment and radiation records at the Sellafield plant and did not depend on tracing parents and receiving correct answers to a questionnaire. About $91 \%$ of both cases and controls were included in this analysis, and a striking association was uncovered between paternal exposure to radiation before conception and the risk of leukaemia in offspring. The association was strong enough to explain the cluster of cases in Seascale and was strongest with exposure to radiation just before conception. No evidence exists in man that germ cell mutations induced by radiation increase susceptibility to leukaemia, so many will want further evidence before accepting the causative explanation.

Two more case-control studies are reported in this issue. Urquhart et al ( $\mathrm{p}$ 687) included 14 cases of leukaemia and nonHodgkin's lymphoma diagnosed under the age of 15 years between 1970 and 1986 in Caithness. ${ }^{8}$ At diagnosis eight had been living within $25 \mathrm{~km}$ of the Dounreay nuclear installation, where an appreciable excess of leukaemia (seven of the eight cases) had been reported between 1979 and 1984. The authors checked the names of case and control fathers against the employment records of the Dounreay nuclear plant and found that the fathers of only two of the eight cases resident within $25 \mathrm{~km}$ of the nuclear establishment had been employed in the nuclear industry before conception of the child (compared with 12 of 25 controls); and none had accumulated preconception doses of more than $100 \mathrm{mSv}$ (the exposure level that the West Cumbria study found was associated with an increased risk) compared with one of 25 controls. Thus paternal occupational radiation exposure did not explain the observed excess of leukaemia. The study's only significant finding was that all five cases with data available had used beaches within $25 \mathrm{~km}$ of Dounreay before their diagnosis, compared with only seven of 16 controls. This apparent excess must be interpreted with caution, however, and could be due to bias or be a chance. finding. It is based on small numbers and no corresponding association was found in West Cumbria.

McKinney and colleagues ( $p$ 681) also studied cases of leukaemia in areas where "clusters" had been reported and an environmental exposure was suspected as the cause. ${ }^{9}$ Only one of the clusters, in West Cumbria, was near a nuclear plant. Many possible aetiological factors to which parents might have been exposed were investigated. Much interest will focus on the authors' conclusion that their findings 
support the hypothesis, generated by the study of Gardner et al, that fathers' exposure to radiation before conception is causal. Unfortunately, in this new study few of the reported radiation exposures have been verified, and no information on dose is available. Also, three of the six fathers of cases who reported prenatal radiation exposure were included in the study of Gardner et al..$^{+}$If these cases are excluded, as would be appropriate for an independent assessment, the evidence suggesting an effect for preconception irradiation is much weaker.

Although the findings from both studies reported in this issue are not incompatible with an effect of paternal preconception radiation exposure of the size described by Gardner et $a l,{ }^{+}$neither offers strong confirmatory evidence. Indeed, the findings in the Scottish study indicate that if the cluster of cases around Dounreay truly results from reasons other than chance the excess cannot be explained through paternal exposure to radiation while working at the Dounreay nuclear plant.

As well as radiation McKinney et al examined many possible causative exposures. If exposure to ionising radiations before conception really does increase the risk of leukaemia then other mutagenic agents might be expected to have a similar effect, and McKinney et al examined exposures before, during, and after pregnancy. They report increased risks associated with several exposures at different periods, including paternal exposure to wood dust, carbon tetrachloride, trichloroethylene, benzene, coal, or graphite and maternal exposure to wood dust. Unfortunately, for none of these is the exposure verified nor the amount of exposure quantified. The strongest link is reported to be with exposure to wood dust before conception in both mothers and fathers. At least some of these findings may be due to chance. The authors made 480 comparisons and a significant result $(\mathrm{p}<0.05)$ could be expected in about 10 to 20 by chance alone. At this stage it would therefore be prudent to regard the study of McKinney et al as having generated some interesting hypotheses rather than providing strong evidence of new aetiological factors.

The most persuasive evidence that factors before conception influence the risk of childhood leukaemia is provided by the finding of a 20-fold increased risk of leukaemia in children with Down's syndrome. How may we assess the leukaemogenic potential of radiation exposure before conception? The findings from the study of Gardner $e^{2} \mathrm{al}^{+}$suggesting an effect of paternal preconception radiation may be an important new lead, but it is important to seek verification of the findings shown in other populations.

Studies are already underway of the children of nuclear workers, but investigation is needed of people who may have conceived children after having been exposed to higher radiation doses than nuclear workers are typically exposed to-in such populations larger effects might be expected. A group of special interest in this respect would be children conceived after their parents had been successfully treated with radiotherapy for malignant or other disease (for example, the children of patients treated with $x$ rays for Hodgkin's disease). This would allow the assessment of the effects of a high radiation dose delivered over a short period. (Relevant to this assessment is the finding that the children of the survivors of the atomic bomb explosions in Japan do not show an increased risk of cancer. ${ }^{10}$ ) If exposure to radiation must occur shortly before conception for leukaemogenesis, as was suggested by the findings of Gardner et al, the studies of the children of people exposed to a high radiation dose in a short period are less relevant. A more informative group would be the children of radiologists, especially of those radiologists who were in practice when radiation exposure levels were comparatively high.

P G SMITH

Head, Department of Epidemiology and

Population Sciences,

London School of Hygiene and Tropical Medicine,

London WCIE 7HT

1 Independent Advisory Group. Investigation of the possible increased evidence of cancer in West Cumbria. London: HMSO, 1984. (Black report.)

2 Committee on Medical Aspects of Radiation in the Environment. Second Report. Investigation of the possible increased incidence of leukaemia in young persons near the Dounreay nuclear establishment, Caithness, Scotland. London: HMSO, 1988.

3 Committere on Medical Aspects of Radiation in the Environment. Third Report. Report on the incidence of childhood cuncer in the West Berkshire and North Hampshire area, in which are situated the Alomic Weapons Reseurch Establishment, Aldermaston, and the Royal Ordnance Factory, Burghfield. London: HMSO, 1989

4 Gardner MJ, Snee MP, Hall AJ, Powell CA, Downes S, Terrell JD. Results of case-control study of leukaemia and lymphoma among young people near Sellafield nuclear plant in West Cumbria.
$B M F 1990 ; 300: 423-9$

5 Gardner MJ, Hall AJ, Snee MP, Downes S, Powell CA, Terrell JD. Methods and basic data of casecontrol study of leukaemia and lymphoma among young people near Sellafield nuclear plant in control study of leukaemia and lymph

6 Smith PG. Comments on the case-control study of Gardner $e t$ al of leukaemia and lymphoma among young people in West Cumbria. Trop Dis Bull 1990;65:R1-6.

7 Beral V. Leukaemia and nuclear installations. BMf 1990;300:411-2.

8 Urquhart JD, Black RJ, Muirhead MJ, et al. Case-control study of leukaemia and non-Hodgkin's lymphoma in children in Caithness near the Dounreay nuclear installation. $B M \mathcal{F}$ 1991;302: $687-92$

9 McKinney PA, Alexander FE, Cartwright RA, Parker L. Parental occupations of children with leukaemia in west Cumbria, north Humberside, and Gateshead. BMJ 1991;302:681-7.

10 Yoshimoto $\mathrm{Y}$, Neel JV, Schull WJ, et al. Frequency of malignant tumors during the first two decades of life in the offspring (Fl) of atomic bomb survivors. Hiroshima: Radiation Effects Research Foundation, 1990. (RERF technical report 4-90.)

\section{Cancer and HIV infection}

\section{Bound to increase}

Well before the AIDS epidemic began doctors recognised that cancers were commoner in immunosuppressed patients, and male homosexuality had been suggested as a risk factor for cancer a decade earlier. Increasingly frequent reports of malignancy in homosexual men appeared during the 1970s: presumably the social changes that allowed homosexual men freedom of expression also allowed their doctors to identify them.

So when a new immunoparetic disease appeared, initially almost exclusively in homosexual men, it should not have been surprising that there were associated cancers. The surprise has been how few there are. Currently only three are recognised: Kaposi's sarcoma, non-Hodgkin's lymphoma, and primary cerebral lymphoma.

Still unexplained, and initially dismissed as harmless, Kaposi's sarcoma may kill or disable by affecting lungs or viscera. It also causes profound psychological distress. The purple blemishes are best treated with local radiotherapy, and if they are caught early a single treatment will give a perfect cosmetic result. Older lesions, however, leak blood into the tissues, causing haemosiderin tattoos that remain after radiation. The radiotherapist is often outstripped by the progress of the disease, and systemic treatment is inadequate. High dose interferon is sometimes effective but may have 